\title{
CD79A Positive
}

National Cancer Institute

\section{Source}

National Cancer Institute. CD79A Positive. NCI Thesaurus. Code C162095.

An indication that CD79A expression has been detected in a sample. 